\title{
Weathering the Infostorm
}

Vincent F. Hendricks and Pelle G. Hansen: Infostorms: How to take information punches and save democracy. Cham, Heidelberg, New York, Dordrecht, and London: Springer, 2014, 148pp, \$19.99

Simon D’Alfonso, dalfonso@unimelb.edu.au

The Information Age is upon us and with it comes a range of interesting ramifications. Investigations into these matters and ways to deal with the glut of information that pervades our modern information societies has become an important research task. In Infostorms, Vincent Hendricks and Pelle Hansen incorporate tools from formal philosophy, social psychology and game theory to explore a range of phenomena involving the diffusion of information among groups and social networks.

Although the social informational phenomena they explore are not particular to this modern age, modern information technologies and social structures have had a significant effect on their extent. While these technologies can greatly facilitate the dissemination of truthful and relevant information, their use can also amplify the pernicious dissemination of false information in cases where phenomena like herding, lemming-effects, cascades, bystander-effects and groupthink occur. Although technologies such as the printing press, radio and television contribute to this potential for negative information diffusion, the advent of the Internet and social media has taken it to a new level. When such a negative diffusion is rapidly amplified due to these technologies the result is known as an 'infostorm'.

The ten chapters of this book are largely independent from one another; it is not a book that develops a major thesis over the course of its chapters. Rather, each of the chapters covers one or two social informational phenomena. If there is one overarching theme, it is that these phenomena fall under a certain umbrella and share some underlying structure. They result from processes that are susceptible to negative outcomes, either via accident or due to manipulation. These outcomes threaten the social and democratic structures they are a part of, a danger which information technologies intensify. By analyzing and better understanding these phenomena we can educate and better equip ourselves to deal with potential infostorm scenarios and safeguard the democratic processes of which they are a part.

The first of these informational phenomena, pluralistic ignorance, bystander-effects and informational cascades are covered in Chapter 2. Via a collection of familiar scenarios and novel examples, the authors basically show what happens when people problematically follow other people to decide what they themselves should do. To put it very simply, pluralistic ignorance occurs when this behavior is due to a lack of information and cascades occur when there is too much information or choice, confusing the decision maker. Many readers are probably familiar with the bystander-effect The authors analyze this phenomenon whereby the likelihood of people aiding an individual in need is inversely related to the number of people at the scene.

In this initial chapter we get a good feel for how the authors will approach the remaining chapters. The examples used to fuel the analyses contain a mixture of personal stories from the authors, generally well-known stories and scenarios that will be familiar to readers and other interesting case studies, particularly ones from the Internet.

Chapter 3 takes a look at public space. Interestingly, public space is not defined here as a physical location where people meet. Rather, public space is understood as a special information structure defined in terms of common knowledge. Common knowledge is amenable to a formal treatment in epistemic logic and the authors appropriately introduce a bit of epistemic logic here to facilitate 
their analysis. By this chapter it starts to become evident that the book's aim is to give an introductory analysis of examples related to each phenomenon rather than going into detailed investigation. Chapter 4 provides an analysis of political freedom. What does it mean to have political freedom in a democracy? The equation `political freedom $=$ individual choice + information + competitive market' is considered.

It may come as little surprise that the way information is presented might influence how we respond to it; form, not just content, matters. In Chapter 5, this framing effect is analyzed and some interesting examples are given where subjects are presented with essentially the same piece of information in two cases but their response differs depending on how the information is presented. Continuing on from this framing phenomenon, Chapter 6 looks at polarization within groups, a most pertinent topic in our modern world. The authors outline an account according to which polarization is due to excessive information selection. One point that I derived from this chapter is the potential problem with online services tailoring user content based on usage profiles and history. To give two examples, Facebook users only see content from networks they have engaged with and Google advertising content is determined by user history. Given that exposure to diverse and differing viewpoints is healthy from a democratic perspective, such limited information selection and lack of exposure to contrary perspectives is problematic.

The phenomenon of bubbles is explored in Chapter 7. While we have all heard of economic bubbles such as the dot-com boom and bust, the bubble phenomenon occurs beyond the world of finance; there are status bubbles, fashion bubbles and art bubbles to name a few. The highlight of this chapter for me was the analysis of science bubbles. The authors discuss how the buzz surrounding an area of scientific research can lead to its overvaluation. Also, they discuss how commercial, regulatory and bureaucratic pressures on academic research today forces practices, strategies and outcomes that do not necessarily correlate with the genuine scientific goals of truth and knowledge. While this issue is perhaps most prevalent in science, it would be interesting to see how this analysis carries over to the humanities.

Chapter 8 analyzes the logic of both group and individual reasoning in a set of situations that share a common structure. Chapter 9 brings together a few different investigations and explains the informational structures of a diverse group of societal phenomena, ranging from blood donation to consumer democracy. Particularly interesting was the look at ghettoization and models explaining neighborhood segregation.

Chapter 10 closes the book and reinforces its main messages, one being the basic fact that while information can be used to 'enlighten and inform individuals and groups', when it is misinformation the diffusion can be damaging and can lead to disastrous consequences. Thus the fact that our access to information is now easier than ever is a double-edged sword with the potential to do more harm than good unless we are vigilant and take steps to protect ourselves from information pitfalls. A robust democracy needs more than just every member having an opportunity to vote. It requires educated citizens who have access to correct information on which to base their decisions.

Furthermore, our system should strive for not just true information but knowledge, true information plus justification or reliability. Basing decision and action upon knowledge makes individuals and groups less susceptible to infostorms. The chapter concludes with a short list of 'guidelines' for how to avoid and deal with the types of negative informational phenomena covered in the book.

Infostorms attempts to understand a range of social/group phenomena in terms of their informational structure. While this enterprise is valid, one point worth making is that in order to explain some scenarios adequately it might be necessary to move beyond its informational structure. Obviously the behavior exhibited by agents in a scenario can be influenced by non-epistemic factors. In Chapter 4 the authors demonstrate a problem with "any claim to the effect that freedom 
of individual choice, conceived as choosing freely with sufficient information, should trivially induce efficiency, enhanced quality and other celebrated effects." They use a simple game-theoretic analysis of a situation to illustrate their point, where the optimal decision made by two agents from an individual perspective results in an outcome which is not optimal for the group. Indeed, in actuality, the informational structure of the problem might have little to no bearing on the outcome of the situation. For example, human agents might be induced by moral motives and make a decision in spite of its game-theoretic non-optimality.

Infostorms does a good job of collecting and analyzing a range of intriguing social informational phenomena using insights from a variety of technical fields. It should be mentioned that while the book "warns against the informational pitfalls which modern information technology may amplify", it does not provide an in-depth investigation into cases where information technology does cause infostorms; examples involving websites and social media are provided in some of the chapters but do not expect to find a detailed technical study into the information technological mechanisms that cause infostorms. While I was hoping for a bit more in this respect, this is not necessarily a bad thing. As the authors probably intended, it makes the book both basic enough to appeal to the general reader and a good academic introduction to the notion of infostorms that can serve to instigate further research into this topic. 


\section{University Library}

\section{- M M I E R R V A gateway to Melbourne's research publications}

Minerva Access is the Institutional Repository of The University of Melbourne

Author/s:

D'Alfonso, S

Title:

Weathering the infostorm

Date:

2015-11

Citation:

D'Alfonso, S. (2015). Weathering the infostorm. Metascience, 24 (3), pp.441-444. https:// doi.org/10.1007/s11016-015-9997-9.

Persistent Link:

http://hdl.handle.net/11343/282539 